\title{
Electrochemical Corrosion Behavior of Nano-coated Ti-6Al-4V Alloy by A Novel Chitosan Nanoparticles/silver Nanoparticles in Artificial Saliva Solution
}

\author{
Amany M.Fekry*, Mohamed S. Hussein \\ Chemistry Department, Faculty of Science, Cairo University, Giza, Egypt.
}

\begin{abstract}
$\mathbf{T}$ HIS paper dealt with two newly done nano-composite films, the first composed of chitosan nanoparticles (CNP) and the second composed of chitosan nanoparticles modified with silver nanoparticles $(\mathrm{CNP}+\mathrm{SNP})$, each one is coated on bare Ti alloy surface. Electrochemical impedance spectroscopy (EIS) and Tafel tests were accomplished to identify the corrosion behavior of the bare Ti alloy surface and the synthesized nano-composite coatings on titanium alloy surface in artificial saliva solution. The morphology of the alloy surface coating was achieved. Besides that, the antibacterial activity for the nano-coatings was examined and linked with the bare Ti alloy. The overall results showed that both the two novel coatings enhance the corrosion protection and the antibacterial activity of the studied alloy, where the corrosion resistance and the antibacterial activity of $(\mathrm{CNP}+\mathrm{SNP})$ nano-composite coating is remarkably greater than CNP coating.
\end{abstract}

Keywords: SEM, EDX, EIS, Chitosan nanoparticles, Silver nanoparticles.

\section{Introduction}

Titanium alloys are commonly used as biomedical dental and orthopedic implant. This is attributed to their great biocompatibility and their desirable physical properties such as its light weight [1,2]. Ti alloys possess great corrosion resistance due to the formation of inert $\mathrm{TiO}_{2}$ layer on its surface in biological fluids. Ti alloys are commonly used in biomedical applications because of their exceptional mechanical properties and biocompatiblity. Unfortunately, Ti-6Al-4V alloy liberate Vanadium and Aluminum ions into the electrolyte because of corrosion and fretting corrosion which cause metal ions build up and wear debris close to the tissues resulting in inflammatory reactions and lead to the resurgery of patient when using it as an implant in the human body [3.4]. Surface dealing by a biocompatible nano-composite coating were accomplished to significantly enhance the wear and corrosion resistance of the alloy by using numerous coating techniques such as sol gel method. This nano-composite coating has effects on the reactivity of the alloy surface, the biochemical reactions in the human body and the alloy surface properties [5].

Chitosan is a very beneficial material in biomedical fields like medicine and protein transporting because of its great biocompatibility, high adsorptivity and its safe use [6]. Chitosan has been used as antibacterial and antifungal active agent. The mechanism of its antibacterial action is that chitosan binds to the negatively charged bacterial surface making distraction and shifting the permeability of the cell membrane which causes cell dying. Chitosan shows antibacterial activity toward positive to Gram and negative to Gram bacteria. In positive to gram bacteria, the bacterial cell wall is entirely build up from peptide polyglycogen network which contains many pores that allow foreign molecules to pass through easily. However, in negative to Gram bacteria the cell wall composed of thin membrane of peptide polyglycogen and an outer membrane that composed of lipopolysacchride, lipoprotein and phospholipids. Fortunately, chitosan has a polymeric muco-adhesion property that can open tight joint and allow paracellular movement of molecules across mucosal delivery of vaccines. Chitosan nanoparticle has greater antibacterial activity than chitosan itself because the 
polycationic chitosan nanoparticles with higher surface charge density interact with the bacterial cell for a quantum size effect. The great surface area of the chitosan nanoparticles permit sstrongly adsorption of chitosan nanoparticles on the bacterial cells and interaction with bacterial cell lead to bacterial cell death[7]. The chitosan nanoparticle was synthesized by ionic gelation method via reaction of acidic solution of chitosan with tripolyphosphate solution [8-
11]. Silver ions and silver based compounds have a great toxicity toward many types of bacteria. Silver nanoparticles (SNP) is a noble metal, little toxic, with a great antimicrobial activity due to its vast increase in surface area that is available for bacteria exposure. So it is utilized widely in medical field. The mechanism of its antibacterial activity is assumed that silver nanoparticles cause cell lysis or cell transduction inhibition $[12,13]$.

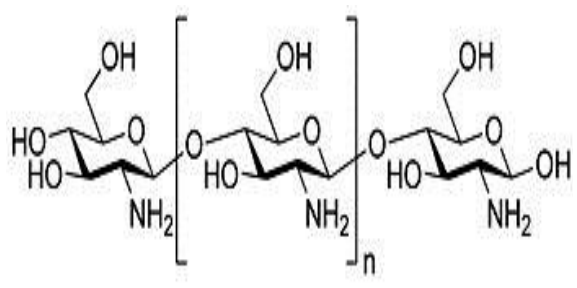

Chitosan

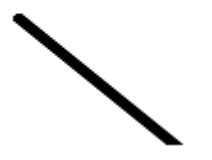
\&

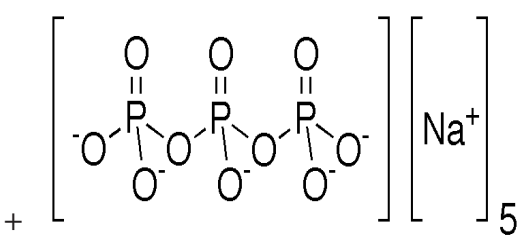

Sodim Tripolyphosphate

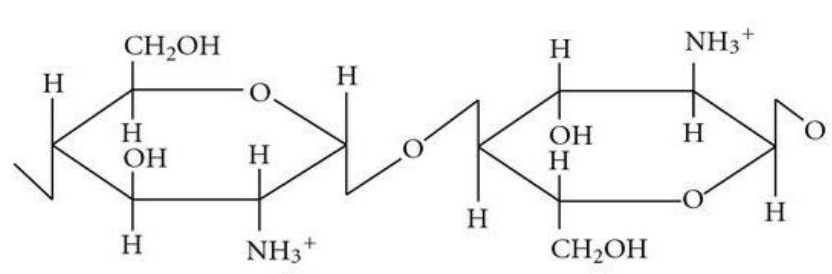

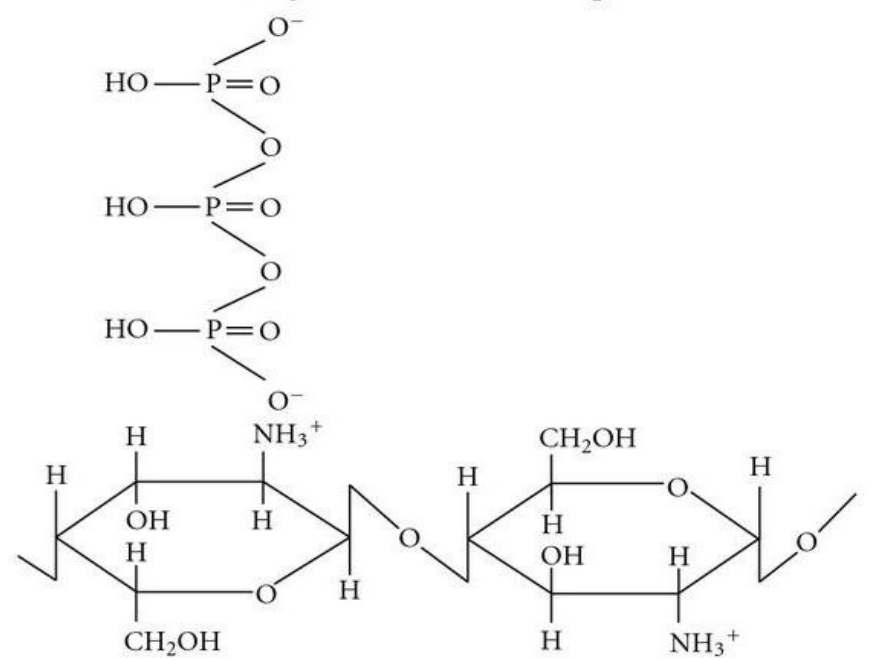

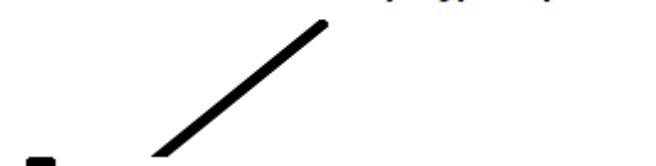

Scheme 1. Nano-chitosan as reaction product of chitosan and Sodium Tripolyphosphate [8]. 
The purpose of this study is to progress the electrochemical corrosion characteristics and antibacterial sensitivity of Ti alloy in synthetic saliva solution with immersion time at $37^{\circ} \mathrm{C}$ for dental requests by using a novel biocompatible nano-composite coating. Our study will focus on the effect of chitosan nanoparticles (CNP) film and chitosan nanoparticles /silver nanoparticles (CNP/SNP) coatings on bare $\mathrm{Ti}$ alloy that soaked in synthetic saliva solution at $37^{\circ} \mathrm{C}$ to inspect the corrosion inhibition and the antibacterial features of each coating. The techniques used are electrochemical impedance spectroscopy (EIS) and Tafel investigations. The newly synthesized nano-coatings were described by both SEM and EDX techniques.

\section{Experimental}

\section{Electrode and cell composition}

Ti-6Al-4V alloy made by Johnson and Matthey (England) with elements (wt\%) is $5.7 \mathrm{Al}$, $3.85 \mathrm{~V}, 0.18 \mathrm{Fe}, 0.038 \mathrm{C}, 0.106 \mathrm{O}$ and $0.035 \mathrm{~N}$ and balance titanium. The alloy is of $0.196 \mathrm{~cm}^{2}$ area and connected to a copper wire then fixed into a cylindrical glass tube by Araldite epoxy resin to set the working electrode. Polishing of the alloy surface was performed using abrasive paper of grades 320 to 2000 respectively with fixing the number of abrasion runs, rinsing it in acetone then ethanol and finally dried in air. The corrosion cell was filled with standard artificial saliva solution and has three-electrodes: working electrode (WE) made of Ti-6Al-4V alloy, counter electrode (CE) made of platinum sheet and a reference electrode (RE) (saturated calomel electrode (SCE))

\section{Chemicals and reagents}

Synthetic saliva solution with a composition: ( 0.72 potassium chloride, 0.22 Calcium chloride dihydrate, 0.6 Sodium Chloride, 0.68 potassium phosphate monobasic, 0.866 Sodium phosphate dibasic dodecahydrate, 1.5 Potasium bicarbonate, 0.06 Potassium Thiocyanate, 0.03 Citric acid) $\mathrm{gm} / \mathrm{L}$ with $\mathrm{pH}=6.5$ [14]. Chitosan from crab shells (85\% deacetylated), acetic acid ( $\geq 99.0 \%)$, Sodium tri-poly phosphate (STPP), Silver nitrate analar grade, Polyvinylpyrrolidone with average MW 360000 from Sigma-Aldrich. Ascorbic acid was purchased from Sigma-Aldrich. Triple distilled water was used in all preparations.

\section{Instrumental works}

The instrument used for electrochemical measurements is IM6e Zahner-electrik, GmbH, Kronach, Germany supported by Thales software.
Tafel lines were maintained at a scan rate of 1 $\mathrm{mV} / \mathrm{s}$ and the impedance tests were accomplished at excitation amplitude of $10 \mathrm{mV}$ in a frequency range of $0.1 \mathrm{~Hz}$ to $100 \mathrm{~Hz}$. Scanning electron microscopy (SEM) and energy dispersive X-ray analysis were achieved by SEM Model Quanta 250 FEG. Each experiment was repetitive for 2-3 times at $37^{\circ} \mathrm{C}$. All potentials were measured virtual to the Standard Calomel Electrode (E = $0.241 \mathrm{~V} / \mathrm{SHE}$ ).

\section{Coatings preparation}

Preparation of Chitosan nanoparticles (CNP) chemically

$1 \%$ chitosan solution was prepared by liquefying 1 gram chitosan in $97 \mathrm{ml}$ distilled water and $2 \mathrm{ml}$ glacial acetic acid keeping stirring for 3-4 hours till complete solubility of chitosan and the solution become clear yellow solution, filter the solution, then dropwise addition of 0.25 $\%$ sodium tripolyphospate (STPP) solution and stirring for $8 \mathrm{~min}$, centrifuge for 30 minutes at 4000 RPM, get rid of the supernatant and rinse the gel formed (CNP) with distilled water [8-11].

\section{Preparation of Silver nanoparticles (SNP) chemically}

$16.6 \mathrm{ml}$ of $5 \%$ Polyvinylpyrrolidone solution (Average MW360000) added to $25 \mathrm{ml}$ of $40 \mathrm{mM}$ silver nitrate solution then make stirring for 8 minutes, afterwards add $16.6 \mathrm{ml}$ of $0.1 \%$ ascorbic acid solution and continue stirring till grey green solution appears then centrifuge for 15-20 minutes at 4000 RPM, get rid of the supernatant and rinse the precipitate (SNP) with distilled water. The first coating (CNP coat) and/or the second coating (CNP+SNP coat) is used to cover the electrode surface by using micropipette and left hanged to dry for 2 hours before using [15].

\section{Antibacterial sensitivity}

The antibacterial sensitivity of the two new coatings (CNP and SNP/CNP coating) were tested against EscherichiaColi (E-Coli which is negative to gram) and Staphylococcus aureus (S. aureus which is positive to gram) bacteria. By means of a reformed Kirby-Bauer disc diffusion scheme [16], where $100 \mu \mathrm{l}$ of the test bacteria were developed in $10 \mathrm{ml}$ of new prepared media and spread in a clean petri dish with incubation at $35-37^{\circ} \mathrm{C}$ for 24-48 hours till they grew to a sum total of about $10^{8} \mathrm{cells} / \mathrm{ml}$ for bacteria. The positive controls for antimicrobial sensitivity are Ampicillin Standard discs (Antibacterial agent), where the negative control is filter discs saturated with $10 \mu$ lof solvent 
(purified water). The organisms will not develop in the field round the disc if it is subtle to the substance. This non grown area called "inhibition zone", this zone diameters were dignified using slipping calipers in millimeters [17-21].

\section{Results and Discussion}

Scanning Electron Microscope (SEM) analysis

Figure $1 \mathrm{a} \& \mathrm{~b}$ show the surface morphologies of coating $\mathrm{C}_{1}(\mathrm{CNP})$ and coating $\mathrm{C}_{2}(\mathrm{CNP}+\mathrm{SNP})$ that cover the bare Ti alloy (Fig.1c) [2] using SEM analysis. From the figure chitosan nano-particles

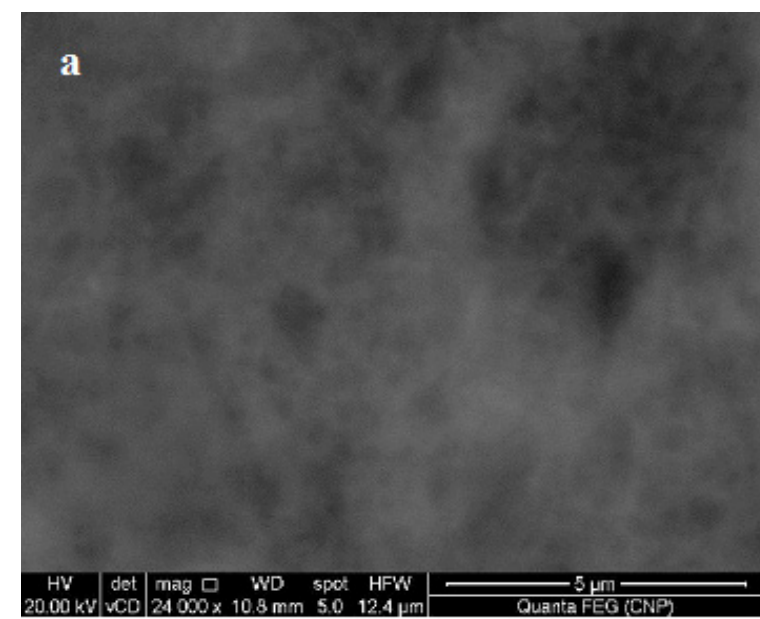

are formed with particle sized nearly about $100 \mathrm{~nm}$ (Fig.1a), while Fig.1b shows the CNP with particle size of less than $100 \mathrm{~nm}$ doped with SNP coating and notifying the particle size of SNP less than 100 $\mathrm{nm}$ that gives more compact thick flowery shape film with larger surface area. The particles are well dispersed as well compared to the bare Ti alloy. The enlarged proportions are due to the connection of silver with chitosan nanoparticles creating a chelate identical assembly with an average size higher than that for chitosan nanoparticles only [11].

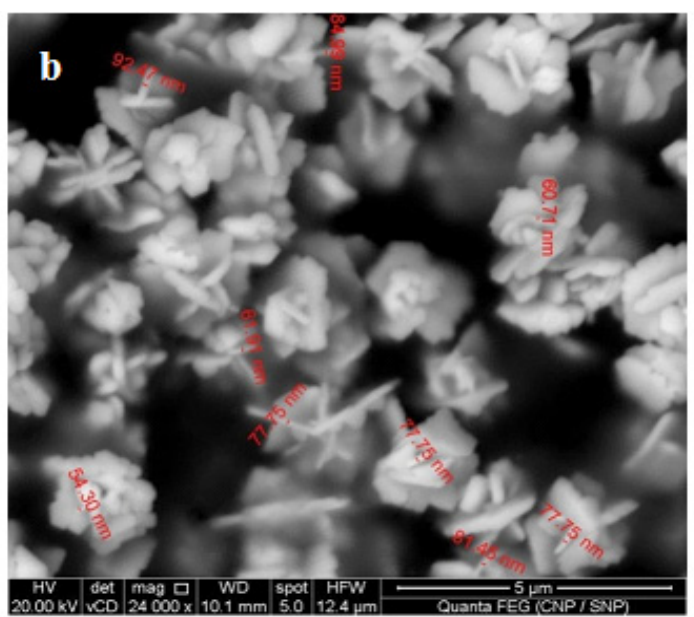

Fig.1a,b.

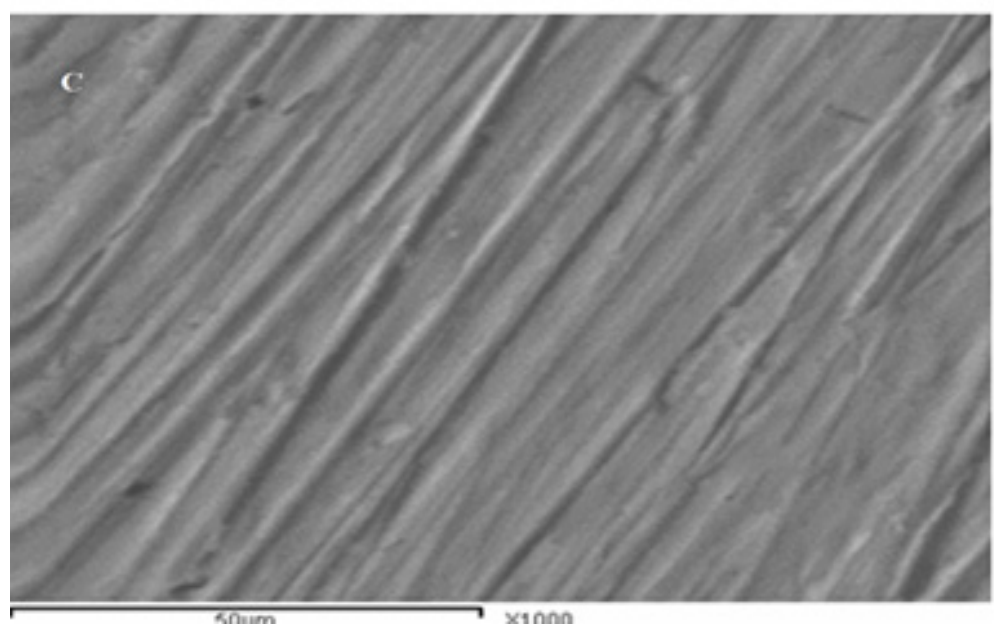

Fig. 1c

Fig.1. SEM images of CNP coating (1a) and (CNP+SNP) coating (1b) compared to the bare Ti alloy (1c) [2].

Energy Dispersive X ray Spectroscopy (EDX)

To recognize the elemental composition of $(\mathrm{CNP}+\mathrm{SNP})$ coating, the EDX spectrum was obtained in Fig.2. It shows that this coating encompasses $\mathrm{C}, \mathrm{N}, \mathrm{O}, \mathrm{Na}$ and $\mathrm{Ag}$ elements. This approves the existence of chitosan with silver nanoparticle in the coating. $\mathrm{Na}$ ions existence is due to using Sodium tri-poly phosphate in the synthesis of chitosan TPP nanoparticles by reaction with chitosan solution. 


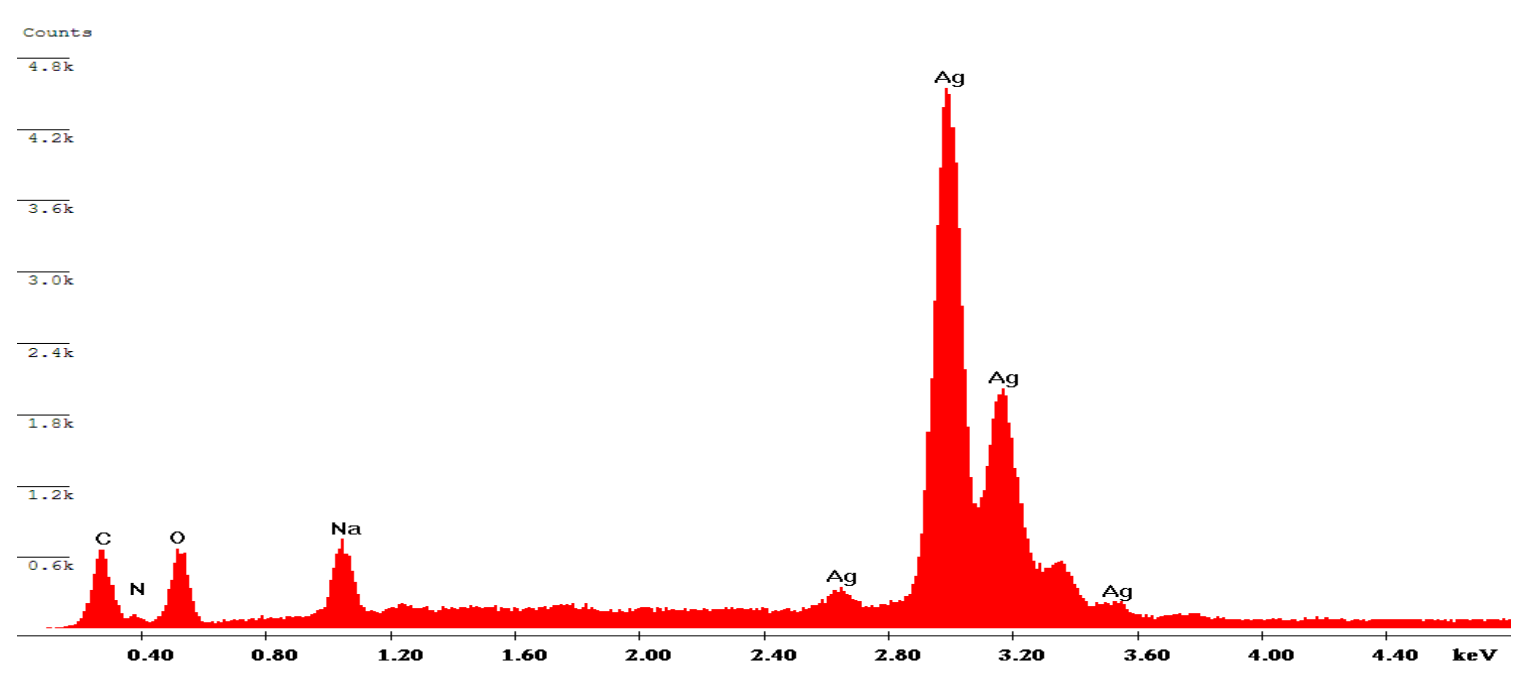

Fig.2. EDX Pattern of (CNP+SNP) coating.

Electrochemical Impedance Spectroscopy (EIS) Impedance measurements for the bare Ti alloy and the coated one soaked in synthetic saliva solution incubated at $37^{\circ} \mathrm{C}$ for 14 days are plotted as Bode and Nyquist plots. Fig.3 (a,b and c) shows the Bode plots for the bare Ti alloy, coated alloy with CNP layer and/or with (CNP+SNP) layer after changed immersion times (2,24, 192 and 336 hours) in artificial saliva incubated at $37^{\circ} \mathrm{C}$ solution. The impedance spectra of the bare Ti alloy displays a gradual rise in impedance and phase peak in the spectra as a function of time, on the other hand, the impedance spectra of the two coated Ti-6Al-4V with CNP (Fig. 3b) and/or with $\mathrm{CNP}+\mathrm{SNP}$ (Fig. 3c) show the same behavior as the bare $\mathrm{Ti}$ alloy with a significant proliferation in the impedance of the coated alloy and a phase angle approaches $90^{\circ}$ indicating higher corrosion resistance than the bare Ti alloy.

Fig. 4 (a,b and c) shows the Nyquist plots for the bare Ti alloy, coated alloy with CNP layer and/or coated alloy with $\mathrm{CNP}+\mathrm{SNP}$ layer in synthetic saliva solution with different immersion times incubated at $37^{\circ} \mathrm{C}$. The shape of the curve in Nyqiust plots of the bare Ti alloy and in the coated one suggests that the corrosion process is controlled well by charge transfer mechanism [22]. The Nyquist plots diameter increases with increasing immersion time and the larger diameter is for CNP+SNP layer. The best fitting for the obtained practical data suggests the same circuit model (Fig. 5) for the three studied electrodes using Thales software indicating the same mechanism. It shows that the circuit consists of $\mathrm{R}_{1} / / \mathrm{Q}_{1}$ parallel combination in series with $\mathrm{R}_{2} / /$ $\mathrm{Q}_{2}$ parallel combination in series with $\mathrm{R}_{\mathrm{s}}$, where $\mathrm{Q}_{1}$ and $\mathrm{R}_{1}$ is the constant phase element (CPE) of the capacitance and the resistance of the outer layer respectively, $\mathrm{Q}_{2}$ and $\mathrm{R}_{2}$ is the constant phase element of the capacitance and the resistance of the internal layer respectively, the corrosion resistance of the coat (CNP coat or $\mathrm{CNP}+\mathrm{SNP}$ coat) is mainly due to the internal layer formed [22]. The constant phase element because of surface roughness effect [23].

The equation that expressing impedance for this model is given by:

$$
Z(\omega)=\mathrm{R}_{\mathrm{S}}+\frac{\mathrm{R}_{1}}{1+R_{1} Q_{1}(j \omega)^{\alpha 1}}+\frac{\mathrm{R}_{2}}{1+R_{2}{ }_{2}{ }_{2}(j \omega)^{\alpha 2}}[23]
$$

$R_{1}$ and $R_{2}$ (in $\Omega$ ): is the outer and the inner layer resistance respectively

$\mathrm{Q}_{1}$ and $\mathrm{Q}_{2}\left(\right.$ in $\left.\mu \mathrm{F} \mathrm{cm} \mathrm{cm}^{-2}\right)$ : is the the outer and the inner layer capacitance respectively. $\omega=2 \pi \mathrm{f}\left(\mathrm{in} \mathrm{rad}_{\mathrm{r}} \mathrm{s}^{-1}\right)$ : is the angular frequency where $\mathrm{f}$ is the frequency in $\mathrm{s}^{-1}$.

$\mathrm{j}=\sqrt{ }(-1)$ : is the imaginary factor

$\alpha_{1}$ and $\alpha_{2}$ is the non-ideality factor of outer and 

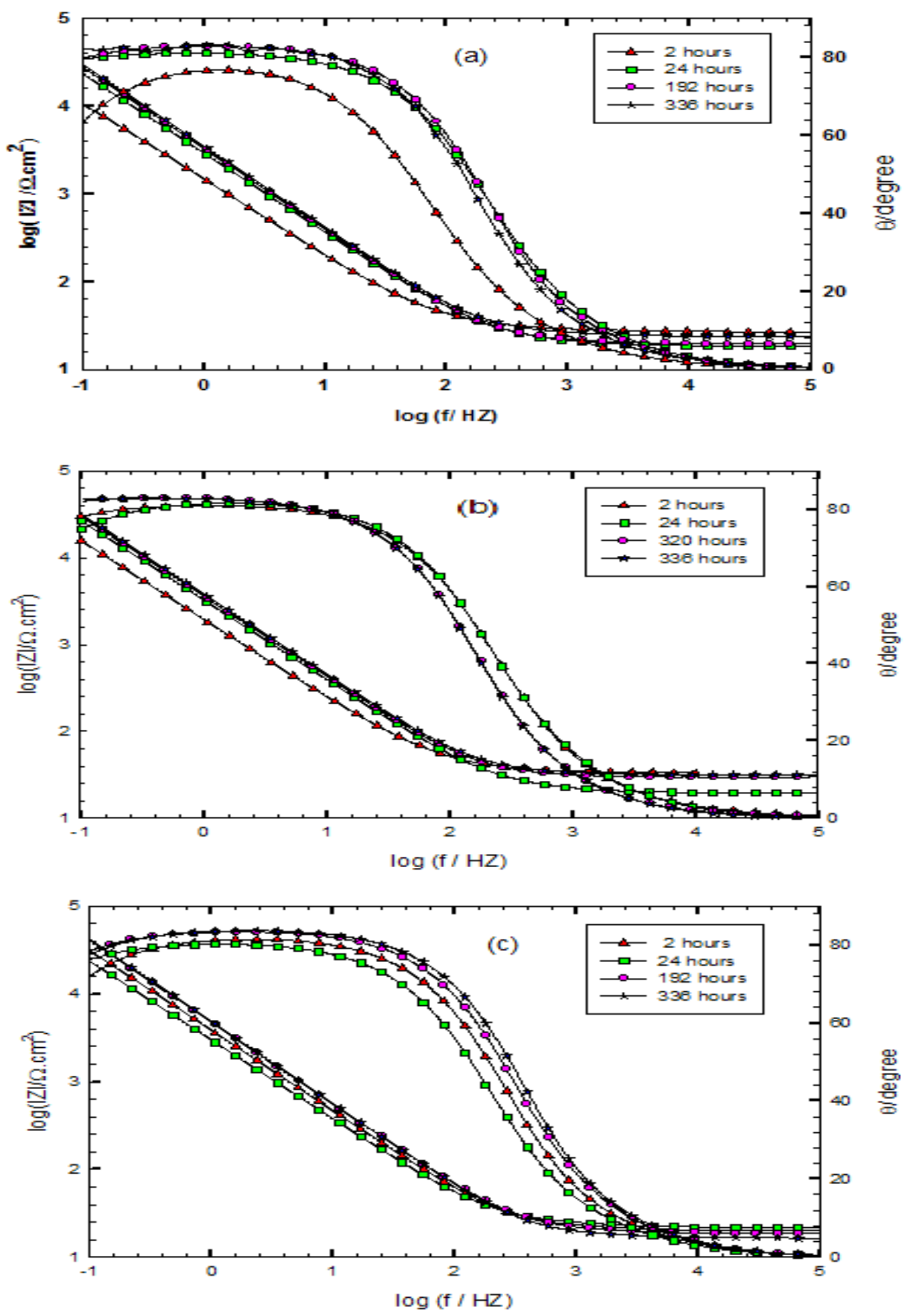

Fig.3. Bode plots for (a) bare Ti alloy; (b) coated with CNP layer and (c) coated with (CNP+SNP) layer in synthetic saliva solution at $37^{\circ} \mathrm{C}$ for 14 days.

Egypt.J.Chem. 61, No.5 (2018) 

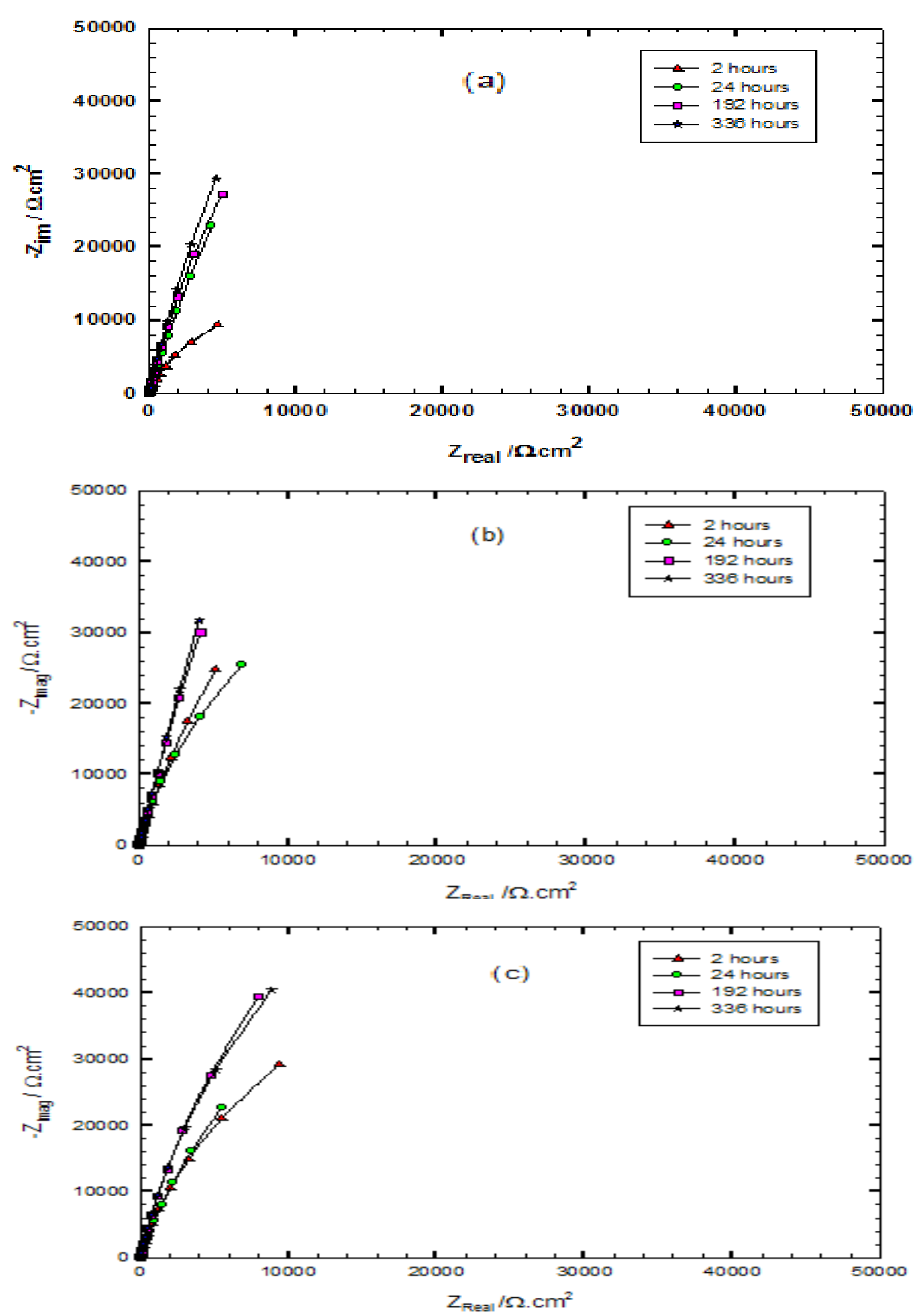

Fig.4. Nyquist plots for (a) bare Ti alloy; (b) coated with CNP layer and (c) coated with ( CNP+SNP) layer in synthetic saliva solution at $37^{\circ} \mathrm{C}$ for 14 days. 


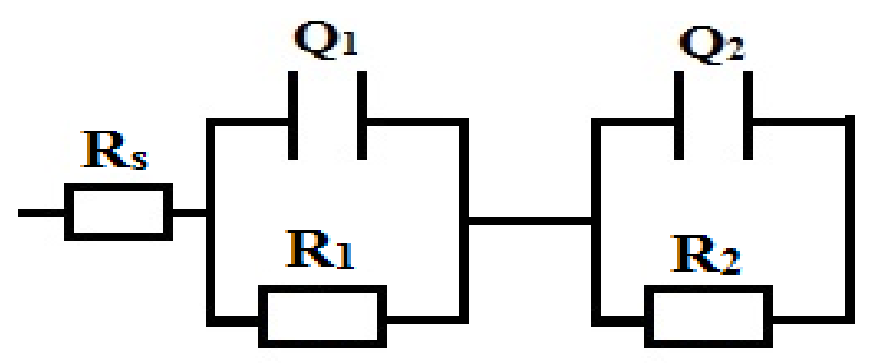

Fig.5. Equivalent circuit model used for fitting.

inner layer capacitances respectively.

The $\alpha$ factor is inserted to account for the nonideality of the capacitor due to surface roughness, adsorption and incomplete homogeneity and it is $0 \geq \alpha \geq 1$ [22]. Table 1 shows the circuit parameters for the three tested alloys, the results indicate that the main corrosion protection is due to the passive inner layer $\left(\mathrm{R}_{2}\right)$ and the higher resistance value is for the (CNP + SNP) coating reaching to $12 \mathrm{M} \Omega \mathrm{cm}^{2}$ with protection efficiency of $82.5 \%$.

\section{Polarization Technique}

Tafel lines of the bare Ti alloy, CNP coated and coated (CNP+SNP) Ti-6Al-4V alloys were performed against standard calomel electrode after 14 days immersion in synthetic saliva solution incubated at $37^{\circ} \mathrm{C}$ by scanning from -1.2 to $0.0 \mathrm{~V}$ with a scanning rate $1 \mathrm{mV} \mathrm{S}^{-1}$. Figure 6 shows the Tafel lines for the 3 cases (the bare Ti alloy, coated with CNP layer and coated with $\mathrm{CNP}+\mathrm{SNP}$ layer) and from it, the Tafel slopes $\beta_{a}$ and $\beta$ can be calculated then the corrosion current density $\left(\mathrm{i}_{\text {corr }}\right)$ and potential $\left(\mathrm{E}_{\text {corr }}\right)$ can be determined by extrapolation and interception of Tafel lines and the interception point indicate the $\mathrm{E}_{\text {corr }}$ and $\mathrm{i}_{\text {corr. }}$ values [20-22]. The results (Table 2) shows that electrochemical corrosion potential $\left(\mathrm{E}_{\text {corr }}\right)$ of $(\mathrm{CNP}+\mathrm{SNP})$ layer coated alloy $(-446 \mathrm{mV})>\mathrm{CNP}$ layer coated alloy $(-729 \mathrm{mV})>$ Bare Ti alloy alloy $(-1004 \mathrm{mV})$ in synthetic saliva solution incubated at $37^{\circ} \mathrm{C}$ for 14 days (336 hour). This indicates that the most positive value of potential is for $\mathrm{CNP}+\mathrm{SNP}$ coating which is attributed to the smallest size for the nanoparticles less than $100 \mathrm{~nm}$ [8]. Also, it gives a lowest corrosion current density of $41.6 \mathrm{nA} \mathrm{cm}{ }^{-2}$ with a high protection efficiency of $82.65 \%$ indicating lowest corrosion rate [2326].

TABLE 1. The fitting data for the three tested Ti alloys without or with coating in artificial saliva solution incubated at $37^{\circ} \mathrm{C}$ for 14 days.

\begin{tabular}{|c|c|c|c|c|c|c|c|c|}
\hline Alloy & $\begin{array}{c}\text { Time } \\
\text { hr }\end{array}$ & $\begin{array}{c}\mathbf{R s} \\
\Omega \mathbf{c m}^{2}\end{array}$ & $\alpha_{1}$ & $\begin{array}{c}\mathbf{R}_{1} \\
\Omega \mathbf{c m}^{2}\end{array}$ & $\begin{array}{c}Q_{1} \\
\mu \mathrm{F} \mathrm{cm} \text { cm }^{-2}\end{array}$ & $\begin{array}{c}R_{2} \\
M \Omega \mathbf{c m}^{2}\end{array}$ & $\begin{array}{c}Q_{2} \\
\mu \mathrm{F} \mathrm{cm} \text { cm }^{-2}\end{array}$ & $\alpha_{2}$ \\
\hline \multirow{4}{*}{ unornamented } & 2 & 26.7 & 0.89 & 25.9 & 15 & 0.8 & 5.0 & 0.84 \\
\hline & 24 & 18.2 & 0.91 & 48.7 & 9.5 & 1.6 & 2.5 & 0.86 \\
\hline & 192 & 19.5 & 0.93 & 74.1 & 8.6 & 1.9 & 2.1 & 0.86 \\
\hline & 336 & 23.7 & 0.93 & 89.5 & 7.9 & 2.1 & 1.9 & 0.87 \\
\hline \multirow{4}{*}{ CNP coat } & 2 & 19.5 & 0.91 & 90.0 & 9.8 & 1.7 & 2.2 & 0.87 \\
\hline & 24 & 19.4 & 0.92 & 187 & 8.3 & 4.6 & 2.1 & 0.92 \\
\hline & 192 & 29.2 & 0.93 & 232 & 7.1 & 5.5 & 1.9 & 0.92 \\
\hline & 336 & 31.5 & 0.93 & 315 & 5.7 & 7.4 & 1.8 & 0.94 \\
\hline \multirow{4}{*}{$\mathrm{CNP}+\mathrm{SNP}$ coat } & 2 & 19.9 & 0.92 & 165 & 9.1 & 2.8 & 1.8 & 0.90 \\
\hline & 24 & 21.7 & 0.90 & 274 & 7.2 & 7.2 & 1.6 & 0.95 \\
\hline & 192 & 18.4 & 0.93 & 406 & 5.0 & 10 & 1.4 & 0.94 \\
\hline & 336 & 16.5 & 0.94 & 644 & 3.1 & 12 & 1.4 & 0.97 \\
\hline
\end{tabular}

Egypt.J.Chem. 61, No.5 (2018) 


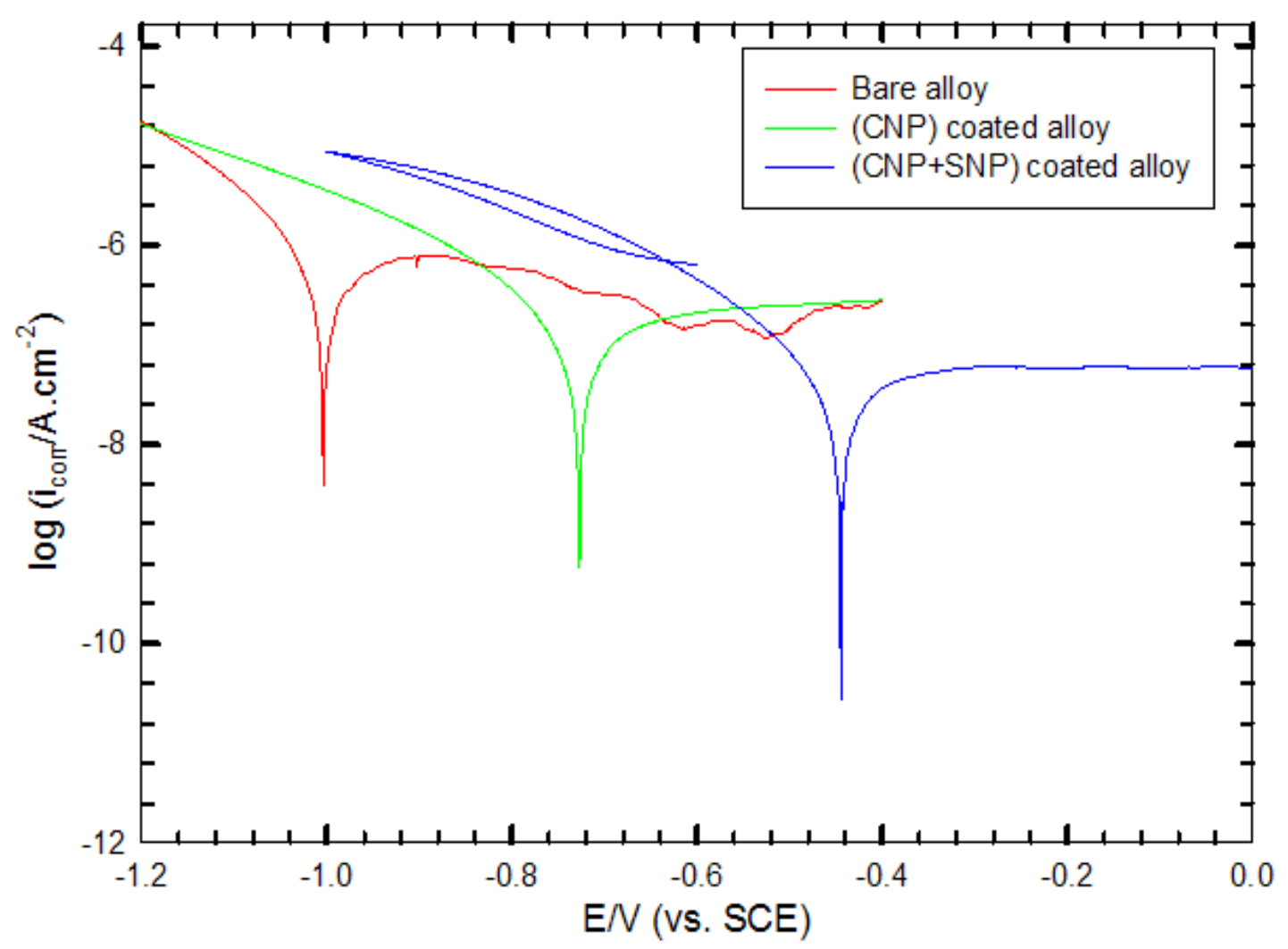

Fig.6. The potentiodynamic polarization curves for bare Ti alloy, CNP coating and CNP+SNP coating after immersion in artificial saliva solution for 14 days, at $37^{\circ} \mathrm{C}$.

TABLE 2. Corrosion parameters of bare and coated Ti alloys in artificial saliva solution after 336 hours of immersion time at $37^{\circ} \mathrm{C}$.

\begin{tabular}{|c|c|c|c|}
\hline Electrodes & $\mathbf{E}_{\text {corr }} /$ & $\mathbf{i}_{\text {corr }} /$ & IE \\
& $\mathrm{mV}$ & $\mathrm{nA.cm}{ }^{-2}$ & $\%$ \\
\hline Bare Ti & -1004 & 239.88 & - \\
CNP coat & -729 & 70.15 & 70.76 \\
CNP SNP coat & -446 & 41.63 & 82.65 \\
\hline
\end{tabular}

\section{Antibacterial activity}

The antibacterial activity test of the CNP $\left(\mathrm{C}_{1}\right)$ and $\mathrm{CNP}+\mathrm{SNP}\left(\mathrm{C}_{2}\right)$ coatings toward E. Coli and $S$. aureus bacteria is shown in Fig 7. Table 3 shows the resulted inhibition zones of CNP layer and CNP+SNP layer, the resulted inhibition zones toward E. Coli and S. aureus bacteria for $\mathrm{CNP}+\mathrm{SNP}$ layer is greater than that obtained in case of CNP layer and this is attributed to the high antibacterial activity of the silver nano particles [8]. This ensures that CNP+SNP is the best coating against bacteria.

Generally and finally, CNP+SNP coating is a nano-coating with compact flowery shape, highest impedance value, lowest corrosion current density and highest antibacterial activity. 

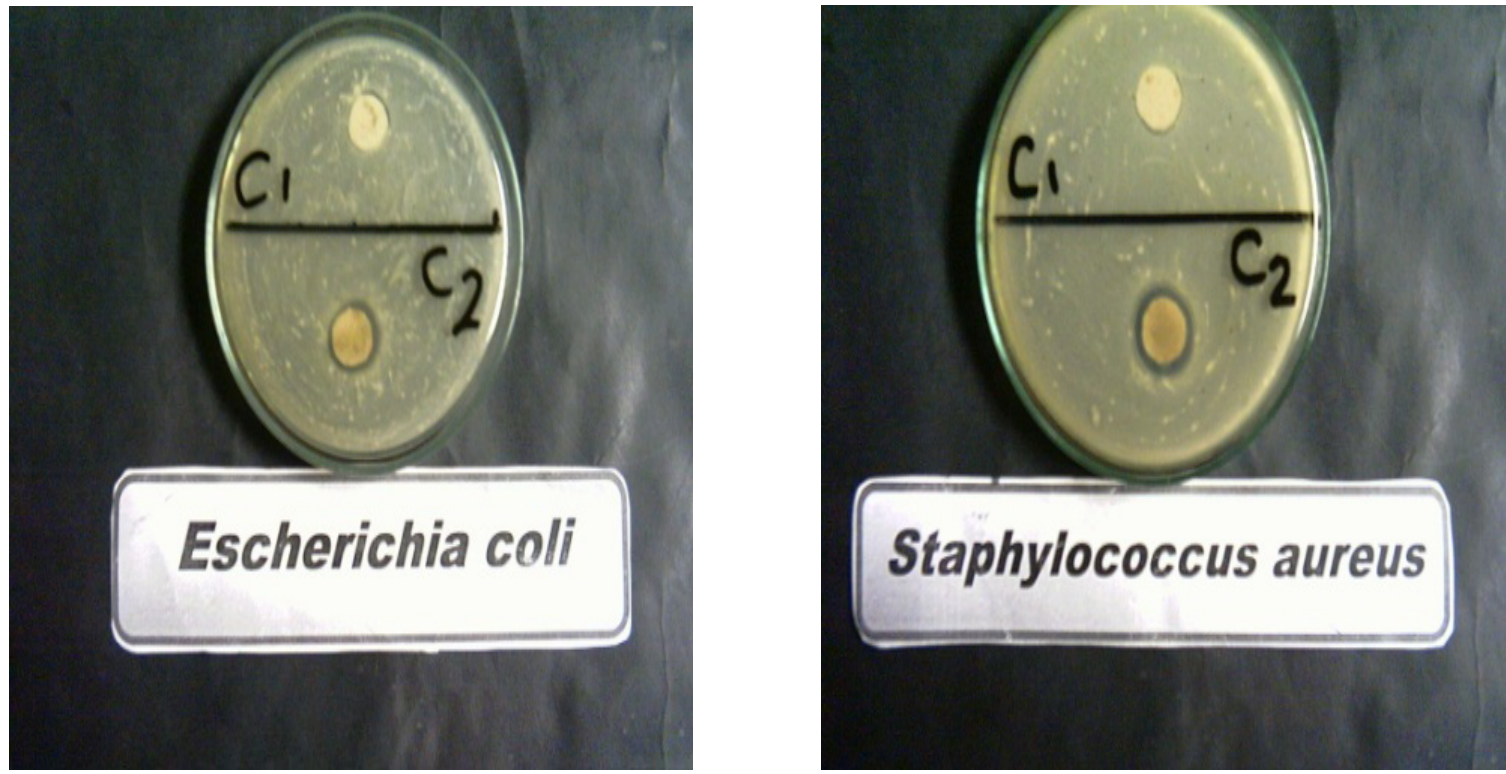

Fig.7. The antibacterial activity tests for $\mathrm{C} 1$ (CNP coating) and $\mathrm{C} 2$ (CNP+SNP coating) toward $E$. coli and $S$. aureus bacteria.

TABLE 3. The inhibition zone diameter ( $\mathrm{mm} 1 / \mathrm{cm}$ sample) of CNP layer $\left(\mathrm{C}_{1}\right)$ and $\mathrm{CNP}+\mathrm{SNP}$ layer $\left(\mathrm{C}_{2}\right)$ toward $E$. coli and $S$. aureus bacteria

\begin{tabular}{|c|c|c|}
\hline \multirow{2}{*}{ Sample } & \multicolumn{2}{|c|}{ Inhibition zone diameter (mm / 1 cm Sample) } \\
\cline { 2 - 3 } & $\begin{array}{c}\text { Escherichia coli } \\
\left(\mathbf{G}^{-}\right)\end{array}$ & $\begin{array}{c}\text { Staphylococcus aureus } \\
\left(\mathbf{G}^{+}\right)\end{array}$ \\
\hline $\begin{array}{c}\mathrm{CNP} \\
\mathrm{C}_{1}\end{array}$ & 12 & 12 \\
\hline$(\mathrm{CNP}+\mathrm{SNP})$ & 14 & 16 \\
$\mathrm{C}_{2}$ & & \\
\hline
\end{tabular}

\section{Conclusion}

- The electrochemical corrosion resistance of bare Ti alloy coated with CNP and/or (CNP+SNP) immersed in synthetic saliva solution incubated at $37^{\circ} \mathrm{C}$ increased with immersion time.

- Novel biocompatible coatings: CNP and $(\mathrm{CNP}+\mathrm{SNP})$ coats enhance the electrochemical corrosion resistance of the Ti-6Al-4V alloy in synthetic saliva solution incubated at $37^{\circ} \mathrm{C}$.

-The electrochemical corrosion resistance of the 3 studied cases are arranged as follow: $(\mathrm{CNP}+\mathrm{SNP})$ coated alloy $>(\mathrm{CNP})$ coated alloy $>>$ bare alloy immersed in synthetic saliva solution at $37^{\circ} \mathrm{C}$.

Egypt.J.Chem. 61, No.5 (2018)
-The CNP coat and CNP+SNP coat shows antibacterial sensitivity toward some positive and negative gram bacteria like E. coli and S.aureus respectively.

- The inhibition zone of the antibacterial activity of CNP+SNP coating is greater than in CNP coating.

-This work will be beneficial in designing a biocompatible implant used in dentistry which has excellent corrosion resistance and a notable antibacterial activity toward negative and positive gram bacteria. 


\section{References}

1. Assis S. L., Wolynec S. and Costa I., Corrosion characterization of titanium alloys by electrochemical techniques, Electrochim.Acta, 51, 1815-1819 (2006).

2. Fekry A.M. and El-Sherif R.M., Electrochemical corrosion behavior of magnesium and titanium alloys in simulated body fluid. Electrochim.Acta, 54, 7280-7285 (2009).

3. de Jonge L.T., Leeuwenburgh S.C.G., van den Beucken J.J.J.P., teRiet J., Daamen W.F., Wolke J.G.C., Scharnweber D. and Jansen J. A., The osteogenic effect of electrosprayed nanoscale collagen/calcium phosphate coatings on titanium, Biomaterials, 31, 2461-2469 (2010).

4. Hryniewicz T., Rokicki R. and Rokosz K., Corrosion and surface characterization of titanium biomaterial after magnetoelectropolishing, Surface \& Coatings Technology, 203, $1508-1515$ (2009).

5. Höhn S.and Virtanen S., Biocorrosion of $\mathrm{TiO}_{2}$ nanoparticle coating of $\mathrm{Ti}-6 \mathrm{Al}-4 \mathrm{~V}$ in DMEMunder specific in vitro conditions, App. Surf. Sci., 329, 356-362. (2015).

6. Ahmed R.A., Fekry A. M. and Farghali R.A., A study of calcium carbonate/multiwalled-carbon nanotubes/chitosan composite coatings on $\mathrm{Ti}-$ 6Al-4V alloy for orthopedic implants, App. Surf. Sci., 285 part B, $309-316$ (2013).

7. Ibrahim H.M., El-Bisi M.K., Taha G.M. and El-Alfy E.A., Chitosan nanoparticles loaded antibiotics as Drug Delivery bio material. J App Pharm Sci, 5 (10), 085-090 (2015).

8. Ponnuraj R., Gopalakrishnan J.K.S., Jeyakumar H. J., Venkateswarlu V. and Narayanan D. S., Formulation and charcterization of Rosuvastatin Calcium nanoparticles, Indo Amer. J. of Phar. Res., ISSN NO: 2231-6876 (2015).

9. Rupareliya1 D., Patel J., Patel K., Upadhyay P. and Shah S., Chitosan: A promising agent for formulation of nanoparticle. JPSBR: 5, 394-398. (2015).

10. Pan Y., Li Y., Zhao H., Zheng J., Xu H., Wei G., Hao J. and Cui F., Bioadhesive polysaccharide in protein delivery system: chitosan nanoparticles improve the intestinal absorption of insulin in vivo, Internat. J. of Pharm., 249, 139-147 (2002).

11. Ali S.W., Rajendran S. and Joshi M., Synthesis and characterization of chitosan and silver loaded chitosan nanoparticles for bioactive polyester, Carbohyd. Polym., 83, 438-446.(2011).

12. Prabhu S.and Poulose E.K., Silver nanoparticles: mechanism of antimicrobial action, synthesis, medical applications, and toxicity effects, International Nano Letters, 2, 32. (2012).

13. Fekry A.M., A new simple electrochemical Moxifloxacin Hydrochloride sensor built on carbon paste modified with silver nanoparticles, Biosensors and Bioelectronics, Biosens. Bioelect., 87, 1065-1070 (2017).

14. Duffó G. S. and Quezada Castillo E., Development of an artificial saliva solution for studying the corrosion behavior of dental alloys, Corrosion; 60(6), 594-602 (2004).

15. Liu B., Deng Y., Hu X., Gao Z. and Sun C., Electrochemical sensing of trichloroacetic acid based on silver nanoparticles doped chitosan hydrogel film prepared with controllable electrodeposition, Electrochim. Acta, 76, 410415 (2012).

16. Mohamed N.R., Khaireldin N.Y., Fahmy A.F. and El-Sayed A.A., Theutility of carbon disulphide and Lawesson'sreagent for synthesis of different fused heterocycles for antimicrobial evaluation, $J$. Heterocyclic Chem., 50,1264-1271 (2013).

17. Bauer A.W., Kirby W.M., Sherris C., Turck M. and Amer J., Antibiotic susceptibility testing by a standardized single disk method, American Journal of Clinical Pathology, 45, 493-496. (1966).

18. Liebowitz L., Ashbee H., Evans E., Chong Y., Mallatova N., Zaidi M. and Gibbs D., A two year global evaluation of the susceptibility of Candida species to fluconazole by disk diffusion, Diagn. Microbiol. Infect. Dis., 4, 27-33. (2001).

19. National Committee for Clinical Laboratory Standards. 1993. Performance VOL. 41, antimicrobial susceptibility of Flavobacteria (1997).

20. National Committee for Clinical Laboratory Standards. Methods for dilution antimicrobial susceptibility tests for bacteria that grow aerobically.Approved standard M7-A3. National Committee for Clinical Laboratory Standards, Villanova, Pa. (1993). 
21. El-Habeeb Abeer A., Al-Saif Foziah A. and Refat Moamen S., Charge transfer complex of some nervous and brain drugs - Part 1: Synthesis, spectroscopic, analytical and biological studies on the reaction between haloperidol antipsychotic drugs with $\pi$-acceptors, J. Mol. Structure, 1034, 1-18. (2013).

22. Shanab S.M.M., Ameer M. A., Fekry A. M., Ghoneim A. A., and Shalaby E. A., Corrosion resistance of Magnesium alloy (AZ31E) as orthopaedic biomaterials in Sodium Chloride Containing antioxidantly active compounds from Eichhorniacrassipes, Int. J. Electrochem. Sci., 6, $3017-3035$ (2011).

23. El-Taib Heakal F. and Fekry A. M., Experimental and Theoretical Study of Uracil and Adenine Inhibitors in Sn-Ag Alloy/Nitric Acid Corroding System, J. Electrochem. Soc., 55, C534-542. (2008).
24. El-Taib Heakal F., Fekry A. M. and Fatayerji M. Z., Electrochemical behavior of AZ91D magnesium alloy in phosphate medium - Part I. Effect of pH, J. App. Electrochem., 39, 583-591. (2009).

25. Fekry A.M., Impedance and hydrogen evolution studies on magnesium alloy in oxalic acid solution containing different anions, Internat. J. Hyd. Ener., 35, 12945-12951 (2010).

26. Fekry A.M., Ghoneim A. A. and Ameer M.A., Electrochemical impedance spectroscopy of chitosan coated magnesium alloys in asynthetic sweat medium, Surf. Coat. Tech., 283, 126132 (2014).

(Received 26/4/2018; accepted 26/6/2018)

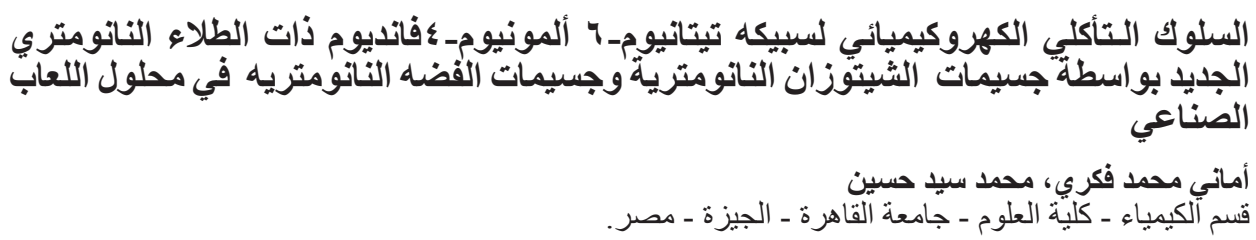

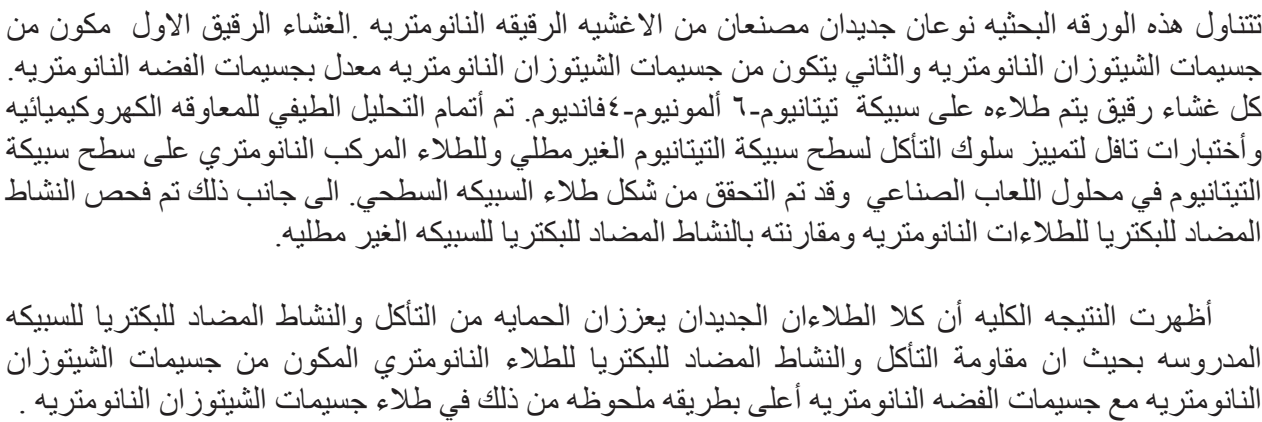

Egypt.J.Chem. 61, No.5 (2018) 